\title{
Prx1 modulates the chemosensitivity of lung cancer to docetaxel through suppression of FOXO1-induced apoptosis
}

\author{
KI-EUN HWANG $^{1 *}$, DO-SIM PARK ${ }^{2 *}$, YOUNG-SUK KIM ${ }^{1}$, BYOUNG-RYUN KIM ${ }^{3}$, SEONG-NAM PARK ${ }^{3}$, \\ MI-KYUNG LEE ${ }^{4}$, SEONG-HOON PARK ${ }^{5}$, KWON-HA YOON ${ }^{5}$, EUN-TAIK JEONG ${ }^{1}$ and HAK-RYUL KIM ${ }^{1}$ \\ Departments of ${ }^{1}$ Internal Medicine, ${ }^{2}$ Laboratory Medicine, Institute of Wonkwang Medical Science, \\ ${ }^{3}$ Obstetrics and Gynecology, ${ }^{4}$ Thoracic and Cardiovascular Surgery and ${ }^{5}$ Radiology, \\ Wonkwang University, School of Medicine, Iksan, Jeonbuk 570-749, Republic of Korea
}

Received February 16, 2013; Accepted April 9, 2013

DOI: $10.3892 /$ ijo.2013.1918

\begin{abstract}
The expression levels of Prx1 are frequently elevated in several human cancers, including lung cancer and may confer increased resistance to treatment. In this study, we investigated the role of Prx1 in docetaxel-induced apoptosis in A549 lung cancer cells. To test whether Prx1 knockdown affected the sensitivity of A549 cells to docetaxel treatment, we generated short hairpin RNA (shRNA) constructs targeting Prx1 and analyzed the effect of Prx1 knockdown on growth and apoptosis. Tumor growth was evaluated in scrambled shRNA- or shPrx1-infected A549 cell tumors receiving docetaxel treatment. In addition, mechanistic information was gathered by western blot analysis from cell lysates of scrambled- and shPrx1-infected A549 cells pretreated with or without LY294002 and subsequently treated with docetaxel. We found that $\operatorname{Prx} 1$ knockdown resulted in enhanced docetaxel-induced cytotoxicity in a dose-dependent manner. In vivo, the growth rate of shPrx1-infected A549 tumors was significantly reduced compared to that of scrambled shRNAinfected A549 tumors. Prx1 knockdown also augmented the inhibitory effects of docetaxel on tumor growth. Prx1 knockdown increased the apoptotic potential through activation of the caspase cascade and suppressed docetaxel-induced phosphorylation of Akt and its substrate forkhead box O1 (FOXO1). Moreover, treatment with the phosphatidylinositol 3-kinase (PI3K) inhibitor LY294002 reduced the phosphorylation of FOXO1 and increased the cytotoxicity of docetaxel in A549 cells. Our findings suggest that Prx1 may modulate
\end{abstract}

Correspondence to: Dr Hak-Ryul Kim, Department of Internal Medicine, Institute of Wonkwang Medical Science, Wonkwang University, School of Medicine, 344-2 Shinyong-dong, Iksan, Jeonbuk 570-749, Republic of Korea

E-mail: kshryj@wku.ac.kr

*Contributed equally

Key words: Prx1, Akt, FOXO1, docetaxel, lung cancer the chemosensitivity of lung cancer to docetaxel through suppression of FOXO1-induced apoptosis.

\section{Introduction}

Lung cancer is the leading cause of cancer-related death worldwide (1). Non-small cell lung cancer (NSCLC) accounts for $\sim 80 \%$ of all lung cancers and most patients with NSCLC present with advanced disease at the time of diagnosis. Chemotherapy has a modest but significant impact on survival and quality of life in patients with NSCLC (2). The development of drug resistance to these anticancer agents represents a major obstacle that needs to be overcome in order to improve the overall response to chemotherapy and the survival rate of lung cancer patients.

Peroxiredoxins are thiol-specific antioxidant proteins. They are found in mammals, yeast and bacteria and are classified largely on the basis of having either 1 (1-Cys) or 2 (2-Cys) conserved cysteine residues (3). Peroxiredoxin 1 (Prx1) is a major member of the 2-Cys peroxiredoxin family and its level is frequently elevated in several human cancers (4-6), including lung cancer (7-9). On the basis of the observations in cultured cells and animal models, a survival-enhancing function of Prx1 has been proposed. Studies by Chen et al (10) have demonstrated a role for Prx1 in radioresistance by using human lung cancer xenograft models. Kim et al (11) also reported that overexpression of Prx1 suppresses ionizing radiation-induced c-Jun $\mathrm{NH}_{2}$-terminal kinase (JNK) activation and apoptosis. However, the mechanisms through which Prx1 regulates the chemotherapeutic response are not clearly understood.

Docetaxel, currently undergoing extensive laboratory investigations and clinical trials, is a taxane derived from the European yew tree (12). It is widely used in the treatment of NSCLC and many other malignancies $(13,14)$. In addition to its efficacy as the first-line treatment for NSCLC, docetaxel alone is the current standard as second-line chemotherapy for recurrent or relapse NSCLC in the USA (15). Docetaxel has been described as an antimitotic agent that binds to $\beta$-tubulin, blocking the cell cycle at G2-M phase and enhancing apoptosis in cancer cells $(16,17)$. Recent findings have indicated that docetaxel may cause numerous biological effects independent of microtubule binding, such as phosphorylation of Bcl-2- 
family proteins, direct activation of mitogen-activated protein kinase (MAPK), induction of pro-apoptotic cytokine genes such as the Fas/CD95 ligand and apoptosis-related proteins such as p53, p21/WAF-1, Bax and certain caspases (18-23). Recent studies have also demonstrated that taxane-induced apoptosis is enhanced by cotreatment with Akt inhibitors $(24,25)$.

Iwao-Koizumi et al (26) have reported that both gene expression patterns observed in breast cancer patients and in vitro transfection findings suggest that redox genes, such as those encoding peroxiredoxins, thioredoxins and glutathioneS-transferase, play a major role in docetaxel resistance. In the present study, we investigated the role of Prx1 in docetaxelinduced apoptosis in A549 lung cancer cells and further tested the hypothesis that the inhibition of Prx1 expression and function may sensitize lung cancer to docetaxel.

\section{Materials and methods}

Materials. RPMI-1640, fetal bovine serum (FBS) and antibiotics were obtained from Gibco BRL Co. (Grand Island, NY). Propidium iodide (PI), 3-(4,5-dimethyl-2-thiazolyl)2,5-diphenyl-2H-tetrazolium bromide (MTT), bicinchoninic acid (BCA), dimethyl sulfoxide (DMSO) and LY294002 were purchased from Sigma-Aldrich (St. Louis, MO). Docetaxel (Taxotere), kindly provided by Aventis Pharma S.A. (Paris, France), was stored as a $100-\mathrm{mM}$ solution in absolute ethanol at $-80^{\circ} \mathrm{C}$ and diluted with medium before use. The following primary antibodies were used: caspase-3, -8, -9, poly(ADPribose) polymerase (PARP) (Santa Cruz Biotechnology, Santa Cruz, CA); serine/threonine protein kinase (Akt), phosphoAkt, forkhead box O1 (FOXO1), phospho-FOXO1, extracellular signal-regulated protein kinase (ERK1/2), phospho-ERK1/2, phospho-JNK, JNK and glyceraldehyde-3-phosphate dehydrogenase (GAPDH) (Cell Signaling Technology, Beverly, MA); and Prx1 (Lab Frontier, Seoul, Korea). Anti-rabbit IgG-conjugated horseradish peroxidase (HRP) antibodies and enhanced chemiluminescent (ECL) kit were purchased from Amersham Pharmacia Biotech (Buckinghamshire, UK).

Prxl knockdown by short hairpin RNA in A549 cells. NCI-A549 human lung cancer cells were obtained from the Korean Cell Line Bank (Seoul, Korea) and subjected to Prx1 knockdown. The pSilencer 5.1 system (Ambion, Austin, TX) was used for the expression of Prx1-targeted short hairpin RNA (shRNA). Sense and antisense oligonucelotide sequences targeting human Prx1, as well as a scrambled control, were described by Chhipa et al (27). The specificity of both the shRNA sequences and the scrambled sequences was confirmed by searching the genome database (BLAST). Oligonucleotides were annealed and cloned into the pSilencer vector. Phoenix packaging cells were transfected with either Prx1-shRNA or scrambled-shRNA expression vector using Lipofectamine 2000 reagent (Invitrogen). The culture supernatants were collected $48 \mathrm{~h}$ after transfection and filtered. A549 cells were then infected with either the Prx1-shRNA or scrambled-shRNA viral preparation in the presence of $4 \mu \mathrm{g} / \mathrm{ml}$ polybrene (Sigma). Cells expressing scrambledshRNA or Prx1-shRNA constructs were designated as control or knockdown, respectively.
Cell viability test. The effect of docetaxel treatment on cell viability was determined by the MTT assay. Scrambledand shPrx1-infected A549 cells were seeded at a density of $3 \times 10^{3}$ cells per well in 96-well plates in triplicate. After $24 \mathrm{~h}$, docetaxel was added at various concentrations and the cells were incubated for $48 \mathrm{~h}$. To determine cell viability, MTT was added to the cell suspension for $4 \mathrm{~h}$. After 3 washes with phosphate buffered saline (PBS; pH 7.4), the insoluble formazan product was dissolved in DMSO. The optical density (OD) of each well was then measured using a microplate reader (Titertek Multiskan; Flow Laboratories, North Ryde, Australia) at $590 \mathrm{~nm}$. The OD due to formazan production in control cells was taken as $100 \%$ viability and all other measurements were expressed as a percentage of the control cell value.

Tumor xenograft studies in nude mice. Five- to six-weekold BALB/c athymic nude mice (Charles River Japan) were housed in cages with HEPA-filtered air (12-h light/dark cycle) and ad libitum access to food and autoclaved water. A549 cells $\left(2 \times 10^{6}\right.$ scrambled-infected cells in groups 1 and 2 , or $2 \times 10^{6}$ shPrx1-infected cells in groups 3 and 4) were injected subcutaneously (s.c.) into both hind legs of each mouse. Mice were randomly assigned to 4 experimental groups of 7 animals each when the implanted tumors reached a volume of $90-130 \mathrm{~mm}^{3}$. Mice in groups 1 and 3 received human $\operatorname{IgG}$ treatment and were designed as controls for groups 2 and 4, respectively. Mice in groups 2 and 4 received docetaxel treatment at $20 \mathrm{mg} / \mathrm{kg}$, intraperitoneally (i.p.), once a week. Mice were monitored until tumors reached a volume of $1300 \mathrm{~mm}^{3}$ or until 3 weeks following the start of treatment. The length (L) and width $(\mathrm{W})$ of tumor mass were measured 3 times per week. Tumor volume was estimated by the formula: volume $=$ $\mathrm{LxW}^{2} / 2$. All procedures were carried out in accordance with our institutional animal care and use policies.

Detection of apoptosis. The degree of apoptosis was determined by measuring the percentage of cells showing hypodiploid DNA content by flow cytometric analysis after PI staining, as originally described by Crissman and Steinkamp (28). Cell cycle analysis was performed using a FACScan equipped with Cell Quest software (Becton-Dickinson, San Jose, CA).

Western blotting. Cells were harvested and lysed by radioimmunoprecipitation assay buffer [50 mM Tris- $\mathrm{Cl}$ (pH 7.4), $1 \%$ NP40, $150 \mathrm{mM} \mathrm{NaCl}, 1 \mathrm{mM}$ EDTA, $1 \mathrm{mM}$ phenylmethylsulfonyl fluoride, $1 \mu \mathrm{g} / \mathrm{ml}$ each of aprotinin and leupeptin and $\left.1 \mathrm{mM} \mathrm{Na}_{3} \mathrm{VO}_{4}\right]$. After centrifugation at 12,000 x g for $30 \mathrm{~min}$, the supernatant was collected and the protein concentration was determined by Lowry method (29). Equal amounts of protein were separated on $12 \%$ sodium dodecyl sulfate-polyacrylamide gel electrophoresis (SDS-PAGE) gels under reduced conditions and subsequently transferred to nitrocellulose membranes. Membranes were blocked with $5 \%$ skim milk in TBS-T [25 mM Tris (pH 7.6), $138 \mathrm{mM}$ $\mathrm{NaCl}$ and $0.05 \%$ Tween-20] for $1 \mathrm{~h}$ and probed with primary antibodies (at 1:1,000-1:5,000). After a series of washes, the membranes were further incubated with secondary antibody (at 1:2,000-1:10,000) conjugated with HRP. Detection of the immunoreactive signal was facilitated using the ECL detection system (Amersham). 
A

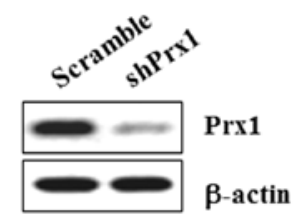

B

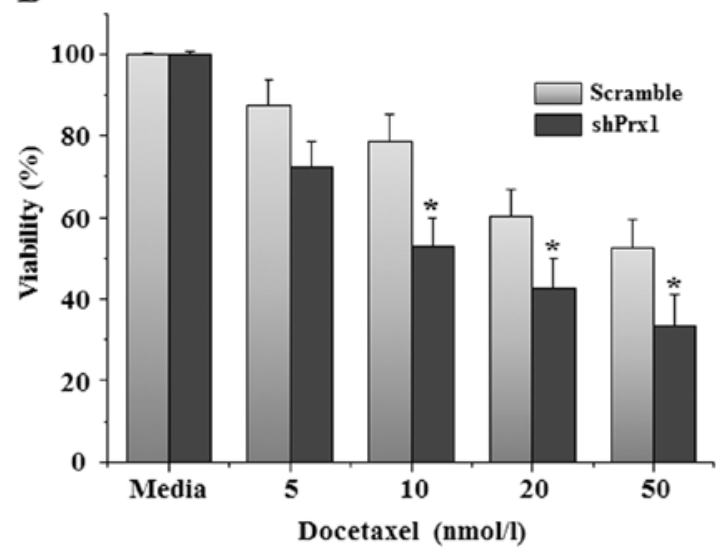

Figure 1. Effects of Prx1 knockdown on the sensitivity of A549 cells to docetaxel. (A) A549 cells were infected with shRNA targeting Prx1 and Prx1 protein expression was assessed by western blot analysis at $48 \mathrm{~h}$ after infection. A scrambled-shRNA construct containing the same number of each nucleotide as the Prx1 shRNA was used as the control. (B) Scrambledand shPrx1-infected A549 cells were treated with different concentrations of docetaxel and viability was measured by MTT assay. Viability of the control cells was set at $100 \%$ and cell survival relative to the control is presented. The data represent the mean $\pm \mathrm{SD}$ of 3 independent experiments. ${ }^{*} \mathrm{p}<0.05$ compared to the control.

Statistical analysis. Each experiment was performed $\geq 3$ times and all values are represented as the means \pm SD of triplicate samples. Student's t-test was used to determine the statistical significance of the results. Values of $p<0.05$ were considered statistically significant.

\section{Results}

Prxl knockdown increases the cytotoxicity of docetaxel in A549 cells. To elucidate whether Prx1 function is important for docetaxel resistance in lung cancer, shRNA targeting Prx1 was generated. As a control, we also generated an empty vector without Prx1 insertion (scrambled). As shown in Fig. 1A, the introduction of Prx1 shRNA abrogated Prx1 protein expression at $48 \mathrm{~h}$ after transfection. Scrambled- and shPrx1-infected A549 cells were treated with docetaxel using a range of concentrations and then cell viability was measured by MTT assay. We found a significant, dose-dependent difference in viability between Prx1 knockdown cells and control cells (Fig. 1B).

Prxl knockdown augments the inhibitory effects of docetaxel on tumor growth. To determine the in vivo relevance of our in vitro findings, we investigated the effects of docetaxel on the growth of scrambled- and shPrx1-infected A549 xenograft
A

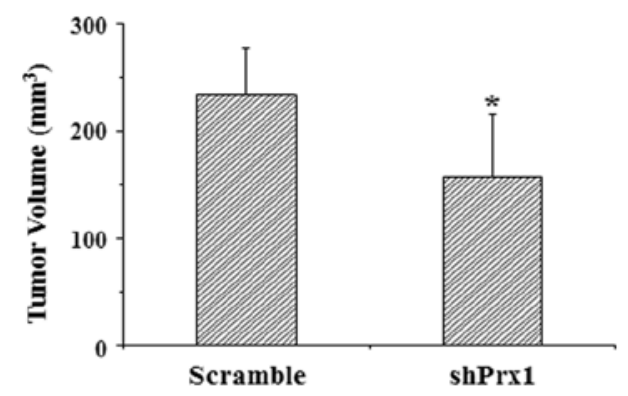

B

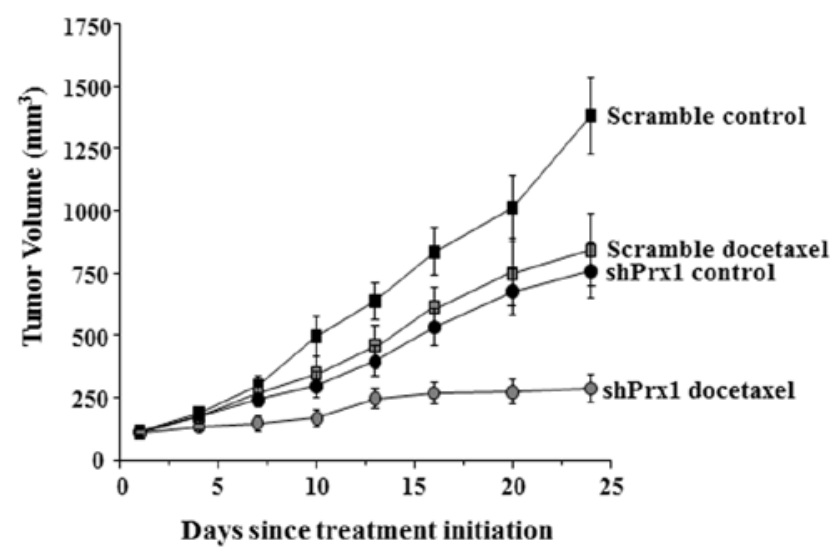

Figure 2. Effects of Prx1 knockdown on the growth of A549 tumors in docetaxel-treated mice. Athymic nude mice were injected s.c. with $2 \times 10^{6}$ scrambled- or shPrx1-infected A549 cells ( $0.2 \mathrm{ml}$ cell suspension) in both hind legs. (A) The volume of scrambled- and shPrx1-infected A549 xenograft tumors at 4 weeks after subcutaneous implantation was measured. "p $<0.05$ compared to scrambled-infected tumors as a control. (B) The mice were randomly divided into 4 groups of 7 animals each: group 1, mice bearing scrambled-infected tumors and receiving human IgG treatment, serving as control for group 2; group 2, mice bearing scrambled-infected tumors and receiving docetaxel treatment at $20 \mathrm{mg} / \mathrm{kg}$, i.p., once a week; group 3, mice bearing shPrx1-infected tumors and receiving human IgG treatment, serving as control for group 4; and group 4, mice bearing shPrx1-infected tumors and receiving docetaxel treatment at $20 \mathrm{mg} / \mathrm{kg}$, i.p., once a week. Tumors were measured 3 times per week. Tumor volume was estimated by the formula: volume $=\mathrm{LxW}^{2} / 2$. Points, mean of 7 animals; bars, SD.

tumors in athymic nude mice. Fig. $2 \mathrm{~A}$ shows a comparison of scrambled- and shPrx1-infected A549 xenograft tumors at 4 weeks after subcutaneous implantation. Interestingly, the growth rate of shPrx1-infected A549 tumors was significantly reduced to only $32.8 \%$ of the control scrambled-infected A549 tumors. We selected 28 mice with similar tumor volumes $\left(90-130 \mathrm{~mm}^{3}\right)$ and analyzed the effects of docetaxel (at $20 \mathrm{mg} /$ $\mathrm{kg}$, i.p., once per week) on tumor growth in mice bearing scrambled- or shPrx1-infected A549 xenograft tumors. Weekly treatment with $20 \mathrm{mg} / \mathrm{kg}$ docetaxel did not result in significant toxicity, including weight loss and mortality, in any of the mice (data not shown). The average volume of tumor growth of A549 cells, evaluated by measuring tumor volume at regular intervals, was decreased in scramble docetaxel compared with scramble control and shPrx1 docetaxel compared with shPrx1 control. With time, scramble-infected A549 control continued to grow, as well as docetaxel-treated and shPrx1-infected 
A
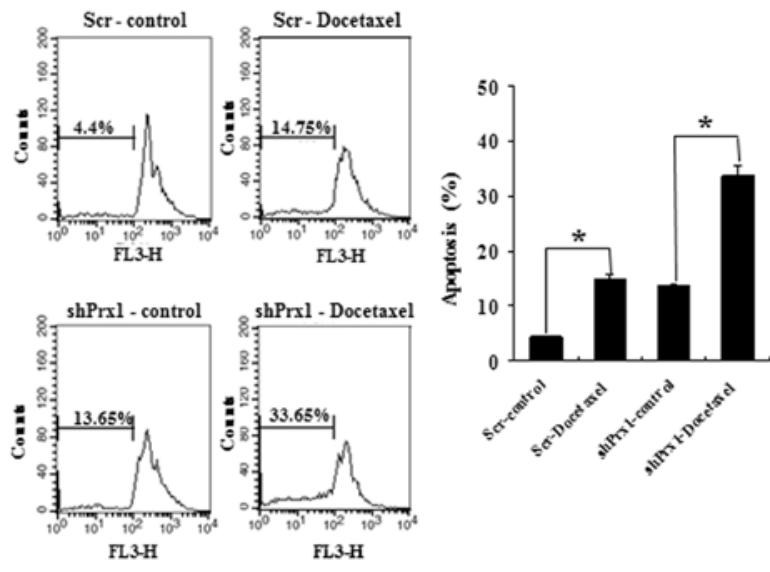

B

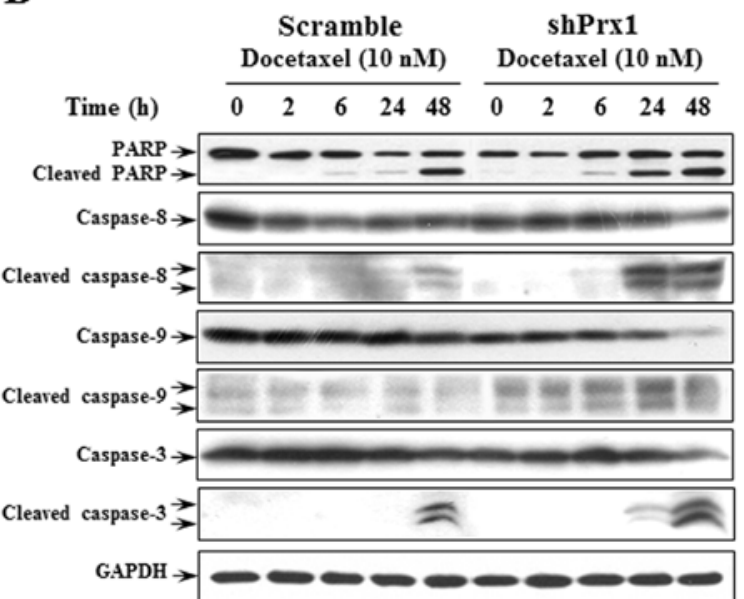

Figure 3. Effects of Prx1 knockdown on caspase-dependent apoptosis induced by docetaxel. (A) Scrambled- and shPrx1-infected cells were incubated with $10 \mathrm{nM}$ docetaxel for $48 \mathrm{~h}$. Apoptosis was quantified by DNA content analysis. The percentage of hypodiploid DNA content is indicated for each test condition. (B) Cells were treated with docetaxel $(10 \mathrm{nM})$ for up to $48 \mathrm{~h}$ and the cell lysates were subjected to $12 \%$ SDS-PAGE to measure the expression of PARP, caspase- $8,-9,-3$ and Prx1.

tumors, whereas the growth of shPrx1-infected tumors was significantly inhibited, reaching only $45 \%$ of the volume of scrambled-infected control tumors. Moreover, compared with other groups, mice bearing shPrx1-infected tumor xenografts showed significantly reduced tumor volume $\left(290.5 \pm 54.3 \mathrm{~mm}^{3}\right)$ after docetaxel treatment (Fig. 2B).

Prxl knockdown enhances caspase-dependent apoptosis by docetaxel. To examine whether the observed growth inhibition was due to enhanced apoptosis, we analyzed apoptosis-induced DNA fragmentation by determining the percentage of hypodiploid DNA content by flow cytometry in PI-stained cells (Fig. 3A). Docetaxel treatment of shPrx1-infected cells caused a greater increase in the accumulation of hypodiploid DNA content than treatment of scrambled-infected cells, with hypodiploid DNA content increasing from 14.75 to $33.65 \%$. Collectively, these data indicate that Prx1 knockdown triggers the activation of an apoptotic signaling pathway mediated by

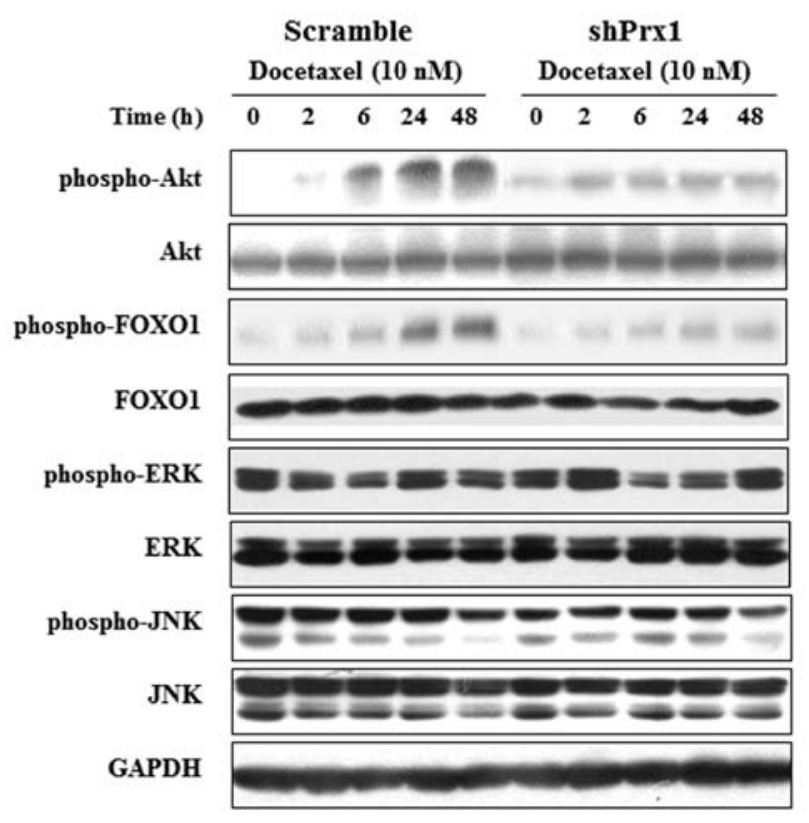

Figure 4. Involvement of Prx1 in docetaxel-induced stress and survival signaling pathways. Scrambled- and shPrx1-infected cells were treated with docetaxel $(10 \mathrm{nM})$ for up to $48 \mathrm{~h}$ and the cell lysates were subjected to $12 \%$ SDS-PAGE to measure the levels of phosphorylated Akt, FOXO1, ERK1/2 and JNK. The membranes used for anti-phospho antibody staining were stripped and used again with antibodies for total Akt, ERK1/2 and JNK. Western blot analysis of GAPDH levels was included to show that equivalent amounts of protein were loaded into each lane.

docetaxel in A549 cells. Using immunoblot analysis, we also found that Prx1 knockdown enhances the cleavage of PARP from a 116- to an $85-\mathrm{kDa}$ protein, a process that plays a major role in apoptosis. To assess the effect of Prx1 knockdown on caspase-dependent apoptosis by docetaxel, scrambled- and shPrx1-infected A549 cells were treated with $10 \mathrm{nM}$ docetaxel for up to $48 \mathrm{~h}$ and then examined by western blotting. Our results showed that Prx1 knockdown led to an increase in the docetaxel-induced activation of caspase- $8,-9$ and -3 (Fig. 3B). These results suggest that Prx1 plays a major role in mediating caspase-dependent apoptosis induced by docetaxel in A549 cells.

Prxl knockdown regulates docetaxel-induced stress and survival signaling pathways. We next examined the role of various signal transduction pathways in modulating docetaxelinduced apoptosis in shPrx 1-infected A549 cells. The activation kinetics of Akt, ERK1/2 and JNK kinases in scrambled- and shPrx1-infected A549 cells treated with docetaxel are shown in Fig. 4. Docetaxel treatment caused a time-dependent increase in Akt phosphorylation in scrambled-infected cells, whereas attenuation of Akt phosphorylation was evident at $24 \mathrm{~h}$ following docetaxel treatment in shPrx1-infected cells. Phosphorylation of Akt continued to decrease in shPrx1infected cells up to $48 \mathrm{~h}$ following docetaxel treatment. In contrast to Akt, phosphorylated ERK1/2 and phosphorylated JNK did not seem to be affected by docetaxel in shPrx1infected cells. In parallel with the studies on Akt activation, we also investigated the possibility that FOXO1 may act as a mediator of apoptosis in these cells. Our results showed that 
A

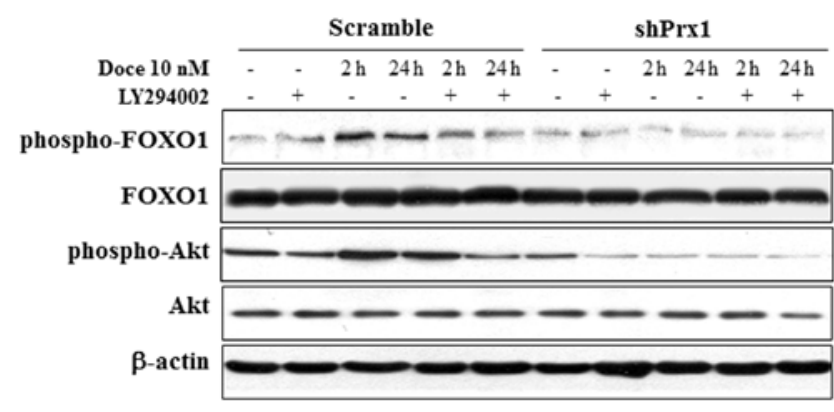

B

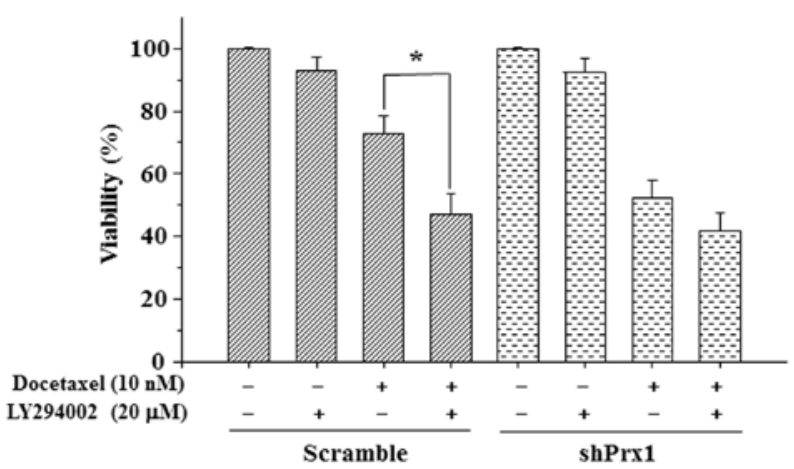

Figure 5. The effects of pharmacological inhibition of Akt on docetaxelinduced phosphorylation of FOXO1 and decreased cell growth. Cells were pretreated with or without the PI3K inhibitor LY294002 and then further incubated in the presence or absence of $10 \mathrm{nM}$ docetaxel. (A) Cell lysates were used to measure the levels of phosphorylated FOXO1 and Akt. (B) Viability was determined using the MTT assay. The data represent the mean $\pm \mathrm{SD}$ of 3 independent experiments. * $\mathrm{p}<0.05$ compared to the control.

Prx1 knockdown suppressed phosphorylation of FOXO1 by docetaxel (Fig. 4).

LY294002 blocks the phosphorylation of FOXO1 by docetaxel and increases the cytotoxicity of docetaxel. To evaluate the functional relevance of Akt activation by docetaxel, we investigated the effects of the phosphatidylinositol 3-kinase (PI3K) inhibitor LY294002 on scrambled- and shPrx1-infected A549 cells. Cells were pretreated with or without LY294002 and then treated with docetaxel and the cell lysates were used to analyze Akt signaling by western blotting. As shown in Fig. 5A, docetaxel treatment resulted in an increase in phospho-Akt and LY294002 treatment decreased this docetaxel-induced Akt activation in scrambled-infected A549 cells. Furthermore, the phosphorylation of FOXO1 was increased by docetaxel treatment in scrambled-infected cells. However, pretreatment with LY294002 restored the phosphorylation of FOXO1 to similar levels as those found in shPrx1-infected cells. Next, to investigate whether downregulation of the PI3K/Akt signaling pathway restored sensitivity to docetaxel, we used the MTT assay. Our results demonstrated that docetaxel treatment decreased cell viability in scrambled-infected cells by $28 \%$, while pretreatment with LY294002 enhanced docetaxelinduced cell death, reducing cell viability by $54 \%$. This effect was similar to docetaxel treatment in shPrx1-infected cells in which viability was reduced by $48 \%$ (Fig. 5B). Together, these data indicated that the PI3K/Akt pathway regulates FOXO1 phosphorylation and activity.

\section{Discussion}

In the present study, we investigated how Prx1 may act to modify the chemosensitivity of lung cancer tumors and focused on elucidating the interplay between Prx1 and docetaxelinduced Akt/FOXO1 activity. Our results indicate that Prx1 knockdown augments the inhibitory effects of docetaxel on tumor growth and increases apoptotic potential through activation of the caspase cascade. Moreover, we found that Prx1 knockdown suppresses docetaxel-induced phosphorylation of Akt and FOXO1. Therefore, we demonstrated that Prx1 provides resistance to docetaxel-induced apoptosis in lung cancer via an Akt-FOXO1 axis.

The most common cause of docetaxel resistance is the multidrug resistance (MDR) phenotype mediated by the overexpression of membrane transport permeability glycoprotein (P-gp), encoded by the MDRl gene (30). Resistance to docetaxel may also result from interference with the steps leading to the induction of apoptosis. These include modulation of $\beta$-tubulin isoforms (31), upregulation of the cell cycle regulatory protein $\mathrm{p} 21^{\text {cipl }}(32)$, inhibition of the proapoptotic protein $\mathrm{BAD}$ and upregulation of prosurvival pathways involving Bcl-2 and PI3K (33). To our knowledge, this is the first study to identify Prx1 as an important mediator of resistance to docetaxel-induced apoptosis in lung cancer.

Prx1 interacts with and modulates the activities of cell survival regulatory proteins to increase radioresistance (8). Activated Akt serves as an important mediator of cell survival, suppressing cell death induced by a number of apoptotic stimuli including chemotherapeutic agents. The activation of Akt is a frequently observed phenomenon following treatment with docetaxel $(34,35)$. Therefore, the activation of Akt by docetaxel may account for desensitization to docetaxel in scrambled-infected A549 cells. The FOXO family of transcription factors is one of the major direct substrates of the protein kinase Akt and is phosphorylated in response to cellular stimulation by growth factors or a variety of stress stimuli, including oxidative stress, heat shock and ultraviolet radiation (36). Many studies have shown that Akt directly phosphorylates FOXO transcription factors (37-39) and the mechanisms through which Akt regulates FOXO transcription factors have been previously elucidated (40). Phosphorylation of FOXO by Akt triggers the rapid relocalization of FOXO proteins from the nucleus to the cytoplasm and results in the inhibition of FOXO-dependent transcription of its target genes, such as FasL and Trail (41-45). Because FOXO is intimately associated with the death-receptor mediated apoptotic pathway, we investigated the possibility that the FOXO family proteins may act as mediators of the increased apoptosis observed in shPrx1-infected A549 cells treated with docetaxel. The FOXO family of transcription factors consists of 4 members: FOXO1 (FKHR), FOXO2 (FOXO6), FOXO3 (FKHRL1) and FOXO4 (AFX). They have overlapping functions and are involved in apoptotic signaling. Differential expression for these isoforms has been demonstrated; for example, FOXO2 has been shown to be expressed primarily in the developing brain, $\mathrm{FOXO} 3$ was found to be highly expressed in the adult brain and FOXO4 
appeared to be mainly expressed in the heart (46). Sunters et al (47) have reported that FOXO3-mediated transcriptional regulation of Bim contributes to the control of the apoptotic response in paclitaxel-treated breast cancer cell lines. We have found that A549 cells express FOXO1, but not other members of the FOXO family (data not shown). We thus examined the effects of docetaxel on phosphorylation of Akt and FOXO1. Our results demonstrated that docetaxel caused an increase in the phosphorylation of both Akt and FOXO1 in a time-dependent manner in scrambled-infected A549 cells, whereas Prx1 knockdown suppressed docetaxel-induced phosphorylation of both these proteins. These findings suggested that neutralization of Prx1 modifies the Akt-FOXO1 axis, increasing the death receptor-mediated extrinsic apoptosis pathway and caspase- 8 activation. Therefore, Prx1 knockdown may provide a mechanism through which docetaxel resistance can be overcome.

In conclusion, Prx1-mediated regulation of FOXO1 transcriptional activity enhances the chemosensitivity of lung cancer tumors to docetaxel treatment. This study provides evidence to support potential future clinical trials of combinations of docetaxel and Prx1 inhibitors in lung cancer. Prx1 may be an attractive target in the development of more effective docetaxel-based therapies in lung cancer treatment.

\section{Acknowledgements}

This study was supported by a grant of the Korean Health Technology R\&D Project, Ministry of Health \& Welfare, Republic of Korea (A120152).

\section{References}

1. Jemal A, Siegel R, Xu J and Ward E: Cancer statistics. CA Cancer J Clin 60: 277-300, 2010.

2. Hotta K, Matsuo K, Ueoka H,Kiura K, Tabata M and Tanimoto M: Meta-analysis of randomized clinical trials comparing cisplatin to carboplatin in patients with advanced non-small-cell lung cancer. J Clin Oncol 22: 3852-3859, 2004.

3. Ree SG, Kang SW, Chang TS, Jeong W and Kim K: Peroxiredoxin, a novel family of peroxidases. IUBMB Life 52: 35-41, 2001.

4. Yanagawa T, Ishikawa T, Ishii T, Tabuchi K, Iwasa S, Bannai S, Omura K, Suzuki H and Yoshida H: Peroxiredoxin I expression in human thyroid tumors. Cancer Lett 145: 127-132, 1999.

5. Yanagawa T, Iwasa S, Ishii T, Tabuchi K, Yusa H, Onizawa K, Omura K, Harada H, Suzuki H and Yoshida H: Peroxiredoxin I expression in oral cancer: a potential new tumor marker. Cancer Lett 156: 27-35, 2000

6. Noh DY, Ahn SJ, Lee RA, Kim SW, Park IA and Chae HZ: Overexpression of peroxiredoxin in human breast cancer. Anticancer Res 21: 2085-2090, 2001.

7. Lehtonen ST, Svensk AM, Soini Y, Paakko P, Hirvikoski P, Kang SW, Saily M and Kinnula VL: Peroxiredoxins, a novel protein family in lung cancer. Int J Cancer 111: 514-521, 2004.

8. Kim HJ, Chae HZ, Kim YJ, Kim YH, Hwangs TS, Park EM and Park YM: Preferential elevation of Prx I and Trx expression in lung cancer cells following hypoxia and in human lung cancer tissues. Cell Biol Toxicol 19: 285-298, 2003.

9. Chang JW, Lee SH, Jeong JY, Chae HZ, Kim YC, Park ZY and Yoo YJ: Peroxiredoxin-I is an autoimmunogenic tumor antigen in non-small cell lung cancer. FEBS Lett 579: 2873-2877, 2005.

10. Chen MF, Keng PC, Shau H, Wu CT, Hu YC, Liao SK and Chen WC: Inhibition of lung tumor growth and augmentation of radiosensitivity by decreasing peroxiredoxin I expression. Int J Radiat Oncol Biol Phys 64: 581-591, 2006.

11. Kim YJ, Lee WS, IP C, Chae HZ, Park EM and Park YM: Prx1 suppresses radiation-induced c-Jun NH2-terminal kinase signaling in lung cancer cells through interaction with the glutathione S-transferase Pi/c-Jun NH2-terminal kinase complex. Cancer Res 66: 7136-7142, 2006.
12. Gligorov J and Lotz JP: Preclinical pharmacology of the taxanes: implications of the differences. Oncologist 9 (Suppl 2): S3-S8, 2004.

13. Posner MR: Docetaxel in squamous cell cancer of the head and neck. Anticancer Drugs 12 (Suppl 1): S21-S24, 2001.

14. Rowinsky EK: The development and clinical utility of the taxane class of antimicrotubule chemotherapy agents. Annu Rev Med 48: 353-374, 1997.

15. Shepherd FA, Dancey J, Ramlau R, Mattson K, Gralla R, O'Rourke M, Levitan N, Gressot L, Vincent M, Burkes R, Coughlin S, Kim Y and Berille J: Prospective randomized trial of docetaxel versus best supportive care in patients with nonsmall-cell lung cancer previously treated with platinum-based chemotherapy. J Clin Oncol 18: 2095-2103, 2000.

16. Jordan MA and Wilson L: Microtubules as a target for anticancer drugs. Nat Rev Cancer 4: 253-265, 2004.

17. Bhalla KN: Microtubule-targeted anticancer agents and apoptosis. Oncogene 56: 9075-9085, 2003.

18. Haldar S, Chintapalli J and Croce CM: Taxol induces bcl-2 phosphorylation and death of prostate cancer cells. Cancer Res 56: 1253-1255, 1996.

19. Haldar S, Basu A and Croce CM: Bcl2 is the guardian of microtubule integrity. Cancer Res 57: 229-233, 1997.

20. Lee LF, Li G, Templeton DJ and Ting JP: Paclitaxel (Taxol)induced gene expression and cell death are both mediated by the activation of c-Jun NH2-terminal kinase (JNK/SAPK). J Biol Chem 273: 28253-28260, 1998

21. Amato SF, Swart JM, Berg M, Wanebo HJ, Mehta SR and Chiles TC: Transient stimulation of the c-Jun-NH2-terminal kinase/activator protein 1 pathway and inhibition of extracellular signal-regulated kinase are early effects in paclitaxel-mediated apoptosis in human B lymphoblasts. Cancer Res 58: 241-247, 1998.

22. Mhaidat NM, Wang Y, Kiejda KA, Zhang XD and Hersey P: Docetaxel-induced apoptosis in melanoma cells is dependent on activation of caspase-2. Mol Cancer Ther 6: 752-761, 2007.

23. Mhaidat NM, Zhang XD, Jiang CC and Hersey P: Docetaxelinduced apoptosis of human melanoma is mediated by activation of c-Jun NH2-terminal kinase and inhibited by the mitogenactivated protein kinase extracellular signal-regulated kinase 1/2 pathway. Clin Cancer Res 13: 1308-1314, 2007.

24. MacKeigan JP, Taxman DJ, Hunter D, Earp HS III, Graves LM and Ting JP: Inactivation of the antiapoptotic phosphatidylinositol 3-kinase-Akt pathway by the combined treatment of taxol and mitogen-activated protein kinase kinase inhibition. Clin Cancer Res 8: 2091-2099, 2002.

25. Hu L, Hofmann J, Lu Y, Mills GB and Jaffe RB: Inhibition of phosphatidylinositol 3'-kinase increases efficacy of paclitaxel in in vitro and in vivo ovarian cancer models. Cancer Res 62: 1087-1092, 2002.

26. Iwao-Koizumi K, Matoba R, Ueno N, Kim SJ, Ando A, Miyoshi Y, Maeda E, Noguchi S and Kato K: Prediction of docetaxel response in human breast cancer by gene expression profiling. J Clin Oncol 23: 422-431, 2005.

27. Chhipa RR, Lee KS, Onate S, Wu Y and Ip C: Prx1 enhances androgen receptor function in prostate cancer cells by increasing receptor affinity to dihydrotestosterone. Mol Cancer Res 7: 1543-1552, 2009

28. Crissman HA and Steinkamp JA: Cell cycle-related changes in chromatin structure detected by flow cytometry using multiple DNA fluorochromes. Eur J Histochem 37: 129-138, 1993.

29. Lowry OH, Rosebrough NJ, Farr AL and Randall RJ: Protein measurement with the Folin phenol reagent. J Biol Chem 193: 265-275, 1951.

30. Dumontet C and Sikic BI: Mechanisms of action of and resistance to antitubulin agents: microtubule dynamics, drug transport and cell death. J Clin Oncol 17: 1061-1070, 1999.

31. Montegomery RB, Bonham M, Nelson PS, Grim J, Makary E, Vessella R and Stahl WL: Estrogen effects on tubulin expression and taxane mediated cytotoxicity in prostate cancer cells. Prostate 65: 141-150, 2005.

32. Yu D, Jing T, Liu B, Yao J, Tan M, McDonnell TJ and Hung MC: Overexpression of ErbB2 blocks Taxol-induced apoptosis by upregulation of $\mathrm{p} 21^{\mathrm{Cip} 1}$, which inhibits $\mathrm{p} 34 \mathrm{Cdc} 2$ kinase. Mol Cell 2: 581-591, 1998 .

33. Wu JD, Haugk K, Coleman I, Woodke L, Vessella R, Nelson P, Montgomery RB, Ludwig DL and Plymate SR: Combined in vivo effect of A12, a type 1 insulin-like growth factor receptor antibody and docetaxel against prostate cancer tumors. Clin Cancer Res 12: 6153-6160, 2006. 
34. Xing H, Weng D, Chen G, Tao W, Zhu T, Yang X, Meng L, Wang S, Lu Y and Ma D: Activation of fibronectin/PI-3K/Akt2 leads to chemoresistance to docetaxel by regulating survivin protein expression in ovarian and breast cancer cells. Cancer Lett 261: 108-119, 2008.

35. Kosaka T, Miyajima A, Shirotake S, Suzuki E, Kikuchi E and Oya M: Long-term androgen ablation and docetaxel up-regulate phosphorylated Akt in castration resistant prostate cancer. J Uro 185: 2376-2381, 2011.

36. Brunet A, Sweeney LB, Sturgill JF, Chua KF, Greer PL, Lin Y, Tran H, Ross SE, Mostoslavsky R, Cohen HY, Hu LS, Cheng HL, Jedrychowski MP, Gygi SP, Sinclair DA, Alt FW and Greenberg ME: Stress-dependent regulation of FOXO transcription factors by the SIRT1 deacetylase. Science 303: 2011-2015, 2004

37. Biggs WH III, Meisenhelder J, Hunter T, Cavenee WK and Arden KC: Protein kinase B/Akt-mediated phosphorylation promotes nuclear exclusion of the winged helix transcription factor of FKHR1. Proc Natl Acad Sci USA 96: 7421-7426, 1999.

38. Kops GJ and Burgering BM: Forkhead transcription factors: new insights into protein kinase B (c-akt) signaling. J Mol Med 77: 656-665, 1999.

39. Nakae J, Park BC and Accili D: Insulin stimulates phosphorylation of the forkhead transcription factor FKHR on serine 253 through a Wortmannin-sensitive pathway. J Biol Chem 274 15982-15985, 1999.

40. Brunet A, Bonni A, Zigmond MJ, Lin MZ, Juo P, Hu LS, Anderson MJ, Arden KC, Blenis J and Greenberg ME: Akt promotes cell survival by phosphorylating and inhibiting a Forehead transcription factor. Cell 96: 857-868, 1999.
41. Suhara T, Kim HS, Kirshenbaum LA and Walsh K: Suppression of Akt signaling induces Fas ligand expression: involvement of caspase and Jun kinase activation in Akt-mediated Fas ligand regulation. Mol Cell Biol 22: 680-691, 2002.

42. Dijkers PF, Medema RH, Lammers JW, Koenderman L and Coffer PJ: Expression of the pro-apoptotic Bcl-2 family member Bim is regulated by the forkhead transcription factor FKHR-L1. Curr Biol 10: 1201-1204, 2000.

43. Modur V, Nagarajan R,Evers BM and Milbrandt J: FOXO proteins regulate tumor necrosis factor-related apoptosis inducing ligand expression. Implications for PTEN mutation in prostate cancer. J Biol Chem 277: 47928-47937, 2002.

44. Kavurma MM and Khachigian LM: Signaling and transcriptional control of Fas ligand gene expression. Cell Death Differ 10: 36-44, 2003.

45. Lee YJ, Park MY and Kang YA: Enhancement of sensitivity of human lung cancer cell line to TRAIL and gefitinib of IGF-1R blockade. Tuberc Respir Dis 63: 42-51, 2007.

46. Greer EL and Brunet A: FOXO transcription factors at the interface between longevity and tumor suppression. Oncogene 24: 7410-7425, 2005

47. Sunters A, Femandez de Mattos S, Stahl M, Brosens JJ, Zoumpoulidou G, Saunders CA, Coffer PJ, Medema RH, Coombes RC and Lam EW: FoxO3a transcriptional regulation of Bim controls apoptosis in paclitaxel-treated breast cancer cell lines. J Biol Chem 278: 49795-49805, 2003. 